\title{
A dimensão regulatória da Psicologia clínica: o impacto da racionalidade dominante nas relações terapêuticas ${ }^{1}$
}

\author{
Maurício da Silva Neubern \\ Centro Universitário de Brasília
}

\begin{abstract}
Resumo
O projeto de se submeter, de diferentes modos, ao paradigma dominante na ciência produziu uma considerável dimensão regulatória da psicologia clínica que coincidiu com diversos momentos de exclusão da subjetividade. Esse enfoque é baseado, em termos gerais, sobre três problemas. Primeiramente, há o problema da legitimidade, segundo o qual, em função de um conhecimento pretensamente confiável e de noções universalistas, os sentidos singulares dos pacientes seriam substituídos por noções consagradas pelas teorias. O segundo problema é o da competência em que as teorias clínicas estariam muito mais imbuídas de noções voltadas à doença, ao déficit e à incapacidade, o que permitiria poucas opções quanto aos eventuais recursos dos pacientes. O terceiro problema seria o do consumo, no qual a ausência de uma discussão crítica sobre o mesmo permitiria a criação de uma cultura em que tanto os serviços quanto o conhecimento seriam consumidos como produtos. O artigo é concluído com o esboço de alguns pontos rumo a uma ética interna que possa estabelecer as relações entre as dimensões separadas no conhecimento e melhor refletir as conseqüências deste na sociedade.
\end{abstract}

Palavras-chave: epistemologia; psicologia clínica; regulação; subjetividade

\begin{abstract}
The regulatory dimension of clinical psychology: the impact of the dominant rationality in therapeutic relationships. This work shows that the project of submitting oneself in different ways to the dominant paradigm in science has produced a considerable regulatory dimension of clinical psychology that has coincided with various moments of subjectivity exclusion. Such focus is in general terms based on three problems. Firstly, there is the problem of legitimacy, which states that due to a pretentiously trustful knowledge and to universalistic notions, patients' singular senses would be substituted with notions once successfully recognized by theories. The second problem is the competence in which the clinical theories would be a lot more empowered with notions regarding sickness, deficit, and incapacity, which would allow for few options in relation to occasional retreat from patients. The third problem would be that of the consumption, in which the lack of a critical discussion could allow the set up of a culture where not only services, but also knowledge would be dealt with as products. The essay is ended with the presentation of propositions toward an internal ethics that could establish the relationship among the separate dimensions in knowing, and toward a better reflection on its consequences in society.
\end{abstract}

Keywords: epistemology; clinical psychology; regulation; subjectivity

$\mathrm{E}$ mbora tenha efetivado muitas críticas ao projeto científico na psicologia, a psicologia clínica também consistiu em um campo marcado pela aspiração ao saber confiável desse mesmo projeto. As reivindicações dos clínicos quanto a um estatuto metodológico próprio não os conduziram a uma ruptura profunda com tais aspirações, pois boa parte dos princípios epistemológicos da ciência moderna permaneceu determinante em seus sistemas e comunidades científicas freqüentemente sem serem questionados ou discutidos (Gonzalez Rey, 1997; Neubern, 2003). De um modo geral, os pressupostos epistemológicos da ciência moderna preconizavam que a confiabilidade dos métodos estaria associada a um conjunto de disjunções, a começar pelas que precisariam ser efetivadas entre as condições iniciais, tidas como aparentes, e as leis gerais subjacentes aos fenômenos, isto é, o que realmente interessaria (Morin, 1991; Santos, 1987; 2000). Uma vez que fosse possível o acesso a essas leis seria possível prever e controlar os fenômenos, o que permitiu aos homens de ciência uma posição privilegiada, pois passaram a atingir um nível de transformação da natureza nunca antes 
visto (Prigogine \& Stengers, 1979). Uma das implicações mais drásticas nesse sentido se deu em termos da brutal imposição do conhecimento sobre o mundo, o que ia desde as inúmeras descaracterizações dos fenômenos para serem reduzidos a objetos de estudo até a supervalorização das noções de previsão e controle. Em síntese, o conhecimento confiável e superior da ciência foi concebido, desde seu nascimento, como inseparável das divisões e do domínio que impunha aos objetos de estudo.

O ímpeto de conhecer o mundo a partir do domínio exercido sobre ele trouxe questionamentos muito incômodos para as ciências humanas e para a psicologia clínica em particular. Por um lado, havia aqueles que buscavam se manter explicitamente fiéis à racionalidade dominante, como no caso da sociologia de Durkheim (1897/1995), que priorizava critérios externos e estatísticos para compreender fenômenos humanos, como o suicídio. Possivelmente, os maiores representantes dessa vertente, em termos de psicologia clínica, provenham das influências do behaviorismo radical (Skinner, 1953/1993), cujas pretensões pareceram querer expandir o conhecimento desenvolvido no laboratório para os diversos cenários sociais, revivendo intensamente o ideal colonizador da racionalidade dominante.

Por outro lado, encontravam-se outras linhas de pensamento que, nos rastros de Weber (1951) e Freud (1900/1996), reivindicaram um estatuto metodológico próprio, alegando principalmente uma natureza distinta de objetos - os sujeitos, as relações sociais - quanto aos objetos da physis, as relações com o contexto, a identidade entre os sujeitos da pesquisa e os pesquisadores, dentre outras (Santos, 1987). Aqui poderiam ser agrupadas as inspirações provenientes da psicanálise, do humanismo e da fenomenologia que, de uma forma geral, sempre se mostraram bastante críticas quanto às pretensões da ciência no estudo do humano. $\mathrm{O}$ ponto interessante nesse processo é que a divisão que ocorreu em termos teóricos e metodológicos não se impôs em termos epistemológicos (Gergen, 1996; Gonzalez Rey, 1997), de maneira que o paradigma geral do conhecimento científico permaneceu intacto em seus mais importantes princípios: a divisão entre sujeito e objeto; a separação entre homem (cultura) e natureza; e a compreensão do conhecimento como algo que reflete isomorficamente o mundo e a posição privilegiada e superior da ciência com relação aos demais tipos de conhecimento (Santos, 1987; 2000).

Na perspectiva de Santos (2000) essa hegemonia da ciência no plano do conhecimento esteve intimamente ligada à hipertrofia do pólo de regulação - composto pelos princípios de mercado, Estado e comunidade - em detrimento do pólo da emancipação - composto pelas racionalidades científica, artística e moral-prática. Mais especificamente, na medida em que o pólo de regulação (ligado às noções de ordem e controle sociais) se impôs sob a égide do princípio do mercado, as ciências passaram a servir como um instrumento de domínio fundamental nas novas organizações sociais, fosse pela ausência quase absoluta de reflexão crí- tica sobre seus impactos sociais, fosse pela associação com a produção de riquezas (Lyotard, 1979). É assim que se considera que as ciências humanas nasceram também sob uma égide regulatória, pois, apesar das críticas que movimentaram contra os sistemas sócio-políticos, suas explicações e procedimentos serviram mais para conciliar os indivíduos com o que existe do que para a promoção de alternativas sociais (Santos, 1989). Uma vez que se buscasse atingir, sob a inspiração da racionalidade dominante, um conhecimento confiável que retratasse a realidade, não restavam muitas opções para os sujeitos a não ser aprenderem a conviver com ela. A própria discussão ética passou a ser concebida em referência a uma realidade externa e incontornável (Gergen, 1996).

O impacto desse conjunto de processos sobre a psicologia clínica foi, ao mesmo tempo, intenso, profundo e sutil. Mesmo abrindo a possibilidade de estudo de questões subjetivas, como as dimensões históricas e vivenciais dos problemas psíquicos (Freud, 1900/1996) e a valorização do humano (Perls, 1973; Rogers, 1961), ela desvencilhou os indivíduos de seus cenários sociais, contribuindo para uma prática freqüentemente alienadora e individualista na qual as questões vividas pelos pacientes não eram qualificadas em suas relações com os cenários sociais e culturais (Gergen \& Kaye, 1998; Pagès, 1993). Isso se deu ainda em função do considerável atraso da psicologia no que diz respeito à reflexão epistemológica iniciada no século XX que tem permitido uma discussão crítica e aprofundada a respeito de seus principais fundamentos (Gonzalez Rey, 1997; Neubern, 2003). Assim, o presente texto busca demonstrar, por meio de três problemas epistemológicos presentes nas relações clínicas e terapêuticas, como a psicologia clínica incorporou pressupostos da ciência moderna, transformando-se numa ciência muito mais voltada para o pólo de regulação. Essa análise coincide com a exclusão da subjetividade presente nas teorias e escolas de inspiração moderna ${ }^{2}$, isto é, sob a égide da racionalidade dominante.

Vale ressaltar um pequeno lembrete sobre esse tema que, vez por outra, é marcado pela polêmica. Embora a dimensão regulatória seja dominante na psicologia clínica, ela também possui momentos emancipatórios de crítica a esse processo que não poderão ser discutidos aqui devido a limitações de espaço. Assim, as críticas aqui levantadas não constituem inteiramente novidade, pois vários autores têm destacado críticas semelhantes em diversas escolas de psicologia, como na fenomenologia e no existencialismo (May, Angel, \& Ellenberger, 1967; Van den Berg, 1955/1999), na psicanálise (Castoriadis, 1975; Guattari, 1979; Natan, 1999; Roustang, 2001) e nos autores que influenciaram ou receberam os impactos da reflexão pós-moderna, geralmente oriundos da terapia familiar e da psicologia social (Anderson, 1997; Anderson \& Goolishian, 1988; Erickson \& Rossi, 1980; Gergen, 1996; Gonzalez Rey, 1997; Neubern, 2003; O’Hanlon \& Wilk, 1987). A presente reflexão será centrada em um diálogo com estes últimos. 
A realidade que se impõe: o problema da legitimidade

A busca de um acesso privilegiado ao real consistiu em um dos principais pilares da influência dominante nas teorias e escolas de psicologia clínica (Gergen, 1996; Gonzalez Rey, 1997). Tratou-se de uma busca obsessiva por elucidar empiricamente aquilo que seria o essencial, o realmente importante na compreensão do psiquismo humano. Sob a égide da racionalidade dominante, as teorias psicológicas promoveram numerosas disjunções, afastando aspectos como os cenários diversos de relações sociais dos sujeitos para se concentrarem em focos específicos, como os indivíduos, onde seria possível ir além do aparente e ilusório para se chegar às essências universais da realidade humana. Em um paralelo marcante com a física, essa empreitada parecia conferir ao humano um estatuto de natureza (physis) que, sob métodos e óticas adequadas, poderia ser conhecida tal qual realmente era. Assim, o indivíduo, depurado de gangas ilusórias, ruídos e fontes de erro, consistia no foco privilegiado para a revelação de uma natureza universal, capaz de explicar e conferir sentido à sua história, seus problemas, sua personalidade e mesmo a seu processo terapêutico.

As semelhanças entre a prática clínica e o laboratório do físico não foram, nesse sentido, casuais. Contudo, havia ainda um conjunto de processos sutis que ocorriam em nível teórico para permitir essa depuração. As categorias psicológicas nem sempre eram abruptas e explícitas na recusa de consideração de outras dimensões além do psiquismo individual. Em numerosas ocasiões, pode-se notar como buscaram subjugar as diversas influências sociais e antropológicas às noções dominantes, conferindo certo psicologismo à boa parte de suas explicações (Barus-Michel \& Giust-Desprairies, 2000; Gaulejac, 1987; Pagès, 1993). Foi assim que problemas complexos e multideterminados, como a violência, a delinqüência, a exclusão social e a drogadição foram, por vezes, qualificados em termos de estruturas de personalidade como perversões e psicopatias, sem se considerar a riqueza contextual presente na construção dessas trajetórias. Dito de outro modo, ao invés de buscar compreender as relações do sujeito com a diversidade de influências que constroem seu cenário, os clínicos, de um modo geral, reduziram tal diversidade ao paradoxo de um indivíduo universal.

Mais especificamente do ponto de vista da relação terapêutica, a busca isomórfica pelas essências universais trouxe sérias implicações. Pela própria organização do paradigma, a busca objetiva do real era antagônica com relação aos processos subjetivos, cujas dimensões complexas e irregulares poderiam ameaçar sua confiabilidade (Neubern, 2003; Santos, 1987). Enquanto a objetividade se calcava sobre noções como a simplificação, a regularidade, o universalismo e a realidade independente, a subjetividade era habitada pela complexidade, pelo irregular, pelo singular, pela qualidade e pela interpretação do mundo. Uma das conseqüências mais importantes dessa discrepância para as relações terapêuticas foi a impossibilidade de aceitar a multiplicidade de interpreta- ções do mundo, já que as realidades dos indivíduos seriam universais e únicas (Gergen \& Kaye, 1998).

As teorias eram compostas de noções e conceitos tidos como consagrados para os quais a diversidade de expressões dos sujeitos era transportada, muitas vezes, de forma linear. Assim, as diferenças de classe social, de história de vida, de raça, de sexo, de nicho familiar, de origem geográfica e cultural passavam despercebidas, pois o que importava eram as informações para as quais as categorias universais eram sensíveis. A heterogeneidade de sentidos e significações criados e desenvolvidos a partir de numerosas influências dava lugar a uma explicação homogênea e compacta respaldada pela teoria. Isso comprometia intensamente a legitimação dos sentidos singulares dos sujeitos que, comumente, encontrariam grandes dificuldades de se verem reconhecidos nas construções teóricas. Porque enquanto as expressões e sentidos singulares dos sujeitos poderiam ser distorcidos e deformados para corresponderem às teorias, estas permaneciam, na maioria das vezes, intocáveis e livres de questionamento. Eram espécies de pontos finais onde as expressões dos pacientes deveriam ganhar inteligibilidade (Neubern, 2001).

A primazia das teorias consagradas implicava numa relação terapêutica assimétrica porque o saber oficial que representavam, por ser único e exclusivo, era pouco tolerante com o saber comum dos pacientes (Anderson, 1997). Tratava-se de uma reedição da aversão da ciência, rigorosa e confiável, pelo senso comum, comumente calcado na opinião e na ausência de profundidade (Santos, 1989). Assim, as relações terapêuticas transformavam-se em processos de imposição de narrativas nos quais as construções de sentido dos pacientes eram sutilmente substituídas pelas perspectivas dominantes dos terapeutas (Gergen \& Kaye, 1998). Como as teorias apresentavam-se alheias e distantes do cotidiano da ação social dos sujeitos, muitos processos, recursos e sentidos destes deixavam de ser problematizados na relação terapêutica, selecionando sobremaneira o que poderia ser explorado no processo terapêutico.

Desse modo, enquanto as teorias pareciam inspirar confiança em muitos pacientes devido a sua autoridade, elas não lhes ofereciam opções muito diferentes de uma submissão a um universo estranho e distante. Pelo fato de se tratar de um saber mais confiável, as teorias e técnicas eram elevadas a uma posição superior. Importavam os recursos para os quais fossem sensíveis, de maneira que tudo o que o paciente trouxesse ou estivesse efetivando na lida com seus problemas deveria ser enquadrado e qualificado segundo perspectivas universais. Do contrário, estariam fadados à indiferença ou ao abandono. Eram tão fortemente protegidas que ofereciam ao clínico um conjunto de recursos que poderiam ser facilmente utilizados para evitar qualquer ataque, como no caso da noção de resistência (Ausloos, 1995). Expressões que não se enquadrassem adequadamente no leque de recursos teóricos e técnicos (em geral, pouco abrangentes) poderiam ser facilmente interpretadas como falta de colaboração, ou resistência.

Sendo assim, o contexto terapêutico, particularmente, tornava-se um cenário estranho para os pacientes pelo fato 
de ser pautado essencialmente por princípios universais. As bases teóricas não eram sensíveis à heterogeneidade de sentidos, nem tampouco assumiam pressupostos de construção na relação com o real (Gergen, 1996; Mahoney, 1991). Eram homogêneas, únicas e isomórficas, o que foi decisivo para a exclusão da subjetividade (Gonzalez Rey, 1997; Neubern, 2003). Assim, universalizaram-se métodos e técnicas, contribuindo-se para que as propostas terapêuticas se tornassem cada vez mais pouco flexíveis na lida com os pacientes. Os contratos terapêuticos são um bom exemplo nesse sentido, pois quanto a eles, cada terapeuta costuma definir a freqüência, o tempo e o preço das sessões em termos únicos, o que é bastante questionável no que diz respeito à diversidade de necessidades dos pacientes (Erickson \& Rossi, 1980).

É por tal razão que é possível considerar que a noção de sujeito, sempre marginalizada na ciência moderna (Morin, 1990; Santos, 1987), foi subjugada à noção de indivíduo na psicologia clínica (Gonzalez Rey, 1997). Enquanto o primeiro implica em auto-agenciamento, em uma relativa autonomia no que se refere às determinações que se lhe impõem e num papel ativo e consciente nas ações sociais e na fabricação de sentidos, o segundo está ligado a noções deterministas, homogêneas e universais, a um objeto dócil produzido pelas teorias psicológicas e que lhe confirma as proposições. Isso permite compreender porque a noção de sujeito foi excluída das relações terapêuticas sob a inspiração dominante: ela iria de encontro a uma teoria de realidade única e exigiria a possibilidade de múltiplas interpretações. Seria em si uma noção subversiva, não se compactuando com uma relação de submissão e tornando-se uma ameaça a qualquer contexto prioritariamente domesticador. Em suma, colocaria para a psicologia o desafio de uma virada rumo à emancipação, o que ainda ela não foi capaz de aceitar integralmente.

Entretanto, vale também ressaltar que a dimensão regulatória da psicologia clínica remete também aos contextos institucionais em que o próprio clínico se insere e que é marcado, basicamente, por duas questões fundamentais. A princípio, encontra-se a autoridade dos mestres fundadores que, na maioria das vezes, não comporta debates e questionamentos. Essa autoridade surgiu provavelmente como uma forma de suprir a ausência de um contexto experimental válido que permitisse um acesso confiável a uma realidade dada e funcionasse como um "fiel da balança" com relação às divergências de idéias (Stengers, 1995). Na psicologia clínica, o surgimento dessas figuras foi acompanhado por um movimento em que, ao mesmo tempo em que foram alçadas a uma condição mítica, afastaram e reprimiram as iniciativas de debate e divergência, sem renunciar a pretensão de um conhecimento confiável ${ }^{3}$. Mais uma vez, as teorias ganhavam o caráter de livro sagrado que exigiam obediência e resignação ao invés de debate e reflexão abertos. Negaram a proposição de Bachelard (1938/1996), segundo a qual no espírito científico é possível venerar o mestre criticando-o e convidando-o ao debate.

Isso remete ao segundo ponto no qual o terapeuta, enquanto sujeito, também teria dificuldades em encontrar espa- ços para uma reflexão questionadora. É certo que nas diversas escolas de psicologia clínica sempre houve autores que, sem uma crítica aberta à liturgia dos mestres e colocando-se fora do alcance dos mecanismos de coerção institucional, conseguiram desenvolver propostas interessantes capazes de lidar com a heterogeneidade dos processos subjetivos. Nesse sentido, concorda-se com o comentário de Roustang (2001) sobre Dolto e Winnicott que, mesmo expressando sua fidelidade a Freud, desenvolveram abordagens que praticamente não guardaram fundamentos e conceitos centrais desse mestre fundador. Tais mudanças, embora da mais alta relevância clínica, não foram problematizadas em nível epistemológico, o que implica em considerar que a noção de sujeito também aí foi mantida como marginal. A conseqüência direta desses processos é que o clínico tornou-se também um indivíduo, porque todo seu universo de expressões, de um modo ou de outro, estava também subjugado à autoridade das teorias. Elas seriam capazes de lhe dizer o que ele sentia e pensava, como isso lhe afligia e o que deveria ser feito sem, contudo, se colocarem como objeto de reflexão e questionamento.

Tais mecanismos regulatórios estariam presentes nos momentos de formação, na terapia pessoal ${ }^{4}$ e em nos próprios momentos de auto-reflexão em que a voz da teoria seria imposta como soberana. Pesava sobre o clínico o mesmo silêncio que subjugava o cientista para que sua subjetividade não interferisse e ameaçasse a confiabilidade do método. Sua presença na relação terapêutica também estava supervisionada pelo universalismo, pelo individualismo e pela tendência ao homogêneo, apesar de poder haver, vez por outra, o risco da marginalidade que poderia até ser considerado pelos demais membros de sua comunidade, desde que não confrontasse abertamente a liturgia dos mestres.

\section{Natureza e patologia: o problema das terapias intermináveis}

A pretensão de um acesso confiável à realidade universal foi intimamente acompanhada por outras duas noções que se impuseram como dominantes em boa parte das escolas de psicologia clínica: natureza e patologia ${ }^{5}$ (Neubern, 2001). Considera-se que, ao buscar ajuda terapêutica junto a um clínico, o paciente colocava-se em um processo sofrido e de poucas opções, no qual sua posição era marcada pela incapacidade e doença. A perspectiva de uma natureza humana consistia na tentativa de conferir aos objetos psíquicos um conjunto de princípios bastante semelhantes aos objetos da physis, de maneira que, indo-se além das aparências ilusórias, chegava-se à revelação de uma natureza que se impunha ao indivíduo de forma determinista (Gonzalez Rey, 1997). Não havia muitas alternativas para a relação terapêutica, pois o que seria possível era a busca de uma forma mais confortável de lidar com uma realidade que não comportaria maiores modificações. Uma vez que um perfil psicológico ou uma estrutura de personalidade fossem definidos não haveria muito a fazer, pois revelariam a natureza dos indivíduos, cuja origem poderia ser genética ou psíquica. Os contextos cultural, his- 
tórico, político, econômico e social não teriam muito a dizer, pois a determinação dessa natureza faria com que ela se impusesse aos demais processos no momento de definir, por exemplo, um indivíduo perverso.

Neste caso específico, a psicologia clínica, em termos epistemológicos, mantinha a dicotomia entre natureza e cultura, como também efetivava um intenso processo de colonização da primeira em direção à segunda, como o fez boa parte das ciências humanas (Santos, 2000). A noção naturalista era ainda marcada por uma perspectiva de perenidade segundo a qual a natureza seria eterna, a-histórica e a-temporal (Gonzalez Rey, 1997), o que trouxe para a prática clínica a delicada perspectiva dos pareceres definitivos. É curioso notar que, embora a psicologia clínica tenha sempre enfatizado os aspectos históricos, o fez, freqüentemente, de modo determinista, reforçando ainda mais a noção de eternidade, como no caso dos diagnósticos e avaliações psicológicos.

De um ponto de vista epistemológico, essas noções se impunham às relações clínicas no sentido da conformação. Não é sem razões que a perspectiva psicanalítica faz referência a uma ferida narcísica (Chertok \& Stengers, 1989) na qual o indivíduo que pensaria decidir sobre sua vida não encontraria muitas escolhas diante das poderosas forças inconscientes. Desse modo, seria necessário que o paciente aprendesse a lidar com essa situação incontornável, de preferência conformando-se a ela e assumindo-a para si. O problema é que, ao caminhar nessa direção, colocaria em risco inúmeras possibilidades que poderiam ser utilizadas a favor de seu processo terapêutico. A princípio, não seria possível um grande leque de criações sobre seus problemas, uma reconstrução dos mesmos, pois a natureza já estava dada, em si e por si. Ao mesmo tempo, não havia muitas opções para a mobilização da rede social, porque, quando não era desconsiderada do processo individual, era convocada apenas em termos dos procedimentos que deveria utilizar com um paciente desse tipo, o que concorria fortemente para a confirmação e reconstrução do diagnóstico em outros setores da vida dos pacientes (Anderson \& Goolishian, 1988).

No entanto, é curioso notar que a pretensão de um acesso privilegiado a essa realidade natural e imutável esteve acompanhada da noção patológica (Neubern, 2001). Sob sua inspiração, o olhar clínico aperfeiçoou-se em regularidades que tendiam ao problema e à incapacidade, conferindo às expressões dos pacientes uma essência doentia, inadaptada e disfuncional (Anderson, 1997; Ausloos, 1995). A linguagem do clínico parecia estar sempre voltada para o que não vai bem, para aquilo que não dá certo, para o que o paciente não realiza ou não é capaz de realizar. Comumente permeada por termos ligados à doença, como sofrimento e angústia, as práticas clínicas davam a entender que o ser humano é essencialmente doente, como no caso das estruturas de personalidade (Bergeret, 1974) que classificavam a diversidade de pessoas em estruturas neuróticas e psicóticas.

A ênfase no patológico contribuía para uma relação de dependência e submissão, como se o paciente possuísse uma necessidade incontestável do auxílio clínico, tido talvez como um dos únicos capazes de lhe oferecer uma ajuda eficaz. Essa autoridade, que nem sempre se confirmou em termos de eficácia (Gergen \& Kaye, 1998), freqüentemente olhava com desprezo ou indiferença para as demais formas de auxílio, como da comunidade e dos grupos religiosos, reeditando a aversão da ciência pelo senso comum (Santos, 1989; 2000). Ao mesmo tempo, fazia valer a proposta de que o trabalho clínico deveria ocupar uma posição central na vida dos sujeitos, um lugar que deveria ser defendido e priorizado com relação aos demais cenários sociais. É interessante notar que a importância atribuída pelo paciente à sua terapia, por exemplo, era associada comumente a indicadores externos como dinheiro, pontualidade, tempo e assiduidade que curiosamente pareciam sintetizar, para os clínicos, a motivação do paciente. A ironia dessa forma de avaliação se dá, sobretudo, caso se considere que tais critérios externos sobrepõem-se, por inúmeras vezes, sobre as próprias noções teóricas de motivação em escolas que sempre privilegiaram o mundo interno.

Essa noção traduzia as diversas expressões dos indivíduos em termos patológicos e incapacitantes, reforçando, junto aos mesmos, a posição de um pessimismo crônico. Incorria-se, assim, em um conjunto de mensagens contraditórias que poderiam levar o paciente à busca de uma solução impossível. O discurso das terapias modernas enfatizava a importância de dedicação a suas propostas terapêuticas, considerando que o esforço e motivação pessoais do paciente seriam fundamentais para um trabalho bem sucedido. Tal sucesso seria atribuído a sua entrega à terapia, sendo ele o autor principal de suas conquistas. Entretanto, esse mesmo discurso o qualificava em termos teóricos e técnicos numa perspectiva pessimista que poderia dificultar consideravelmente o sucesso do trabalho. Se o processo dependia tanto do indivíduo, e este era essencialmente patológico, ele tenderia a se arrastar por muito tempo em meio a essa contradição insolúvel.

O paciente era desprovido de sua condição de sujeito e diluído numa teia de determinismos. Não era compreendido em seus próprios cenários de fabricação de sentidos (Gergen \& Kaye, 1998; Gonzalez Rey, 1997) e, mais que isso, era concebido como um ser essencialmente doente a ser tratado em um setting muito mais sensível a desvendar problemas que a construir soluções (O’Hanlon \& Wilk, 1987). Todo esse conjunto de ingredientes parecia fazer com que a terapia se tornasse uma espécie de maldição, incorrendo em variados momentos de mal estar devido à posição delicada em que o paciente era colocado - posição que parecia tender a um processo sem fim, pois, mesmo que se esforçasse ao máximo, jamais deixaria de ser um doente. É como se o paciente sofresse a mesma condenação eterna recebida por Sísifo ${ }^{6}$, sem, no entanto, ter cometido os mesmos erros que ele. As conseqüências e implicações do casamento entre noções de conhecimento universal e confiável, natureza e patologia foram variadas. Por um lado, contribuíram para uma compreensão generalizada segundo a qual todos as pessoas necessitariam de terapia, a ajuda profissional seria a mais adequada para tanto e que, devido à condição doentia do gênero humano, as tera- 
pias deveriam ser longas para serem eficientes (Melchior, 1998; O’Hanlon \& Wilk, 1987). Trata-se, na ótica aqui adotada, de uma forma de intervenção rumo ao insolúvel, muito mais voltada, em termos epistemológicos, para a promoção do conhecimento e explicação do que para a pragmática, sem, contudo, ter construído uma base de resultados mais seguros que pudesse sustentar tamanha autoridade.

Por outro lado, essa mesma rigidez institucional e epistemológica favoreceu o desenvolvimento de uma marginalidade que leva a pensar muitas questões. É possível cogitar que, para que as terapias cheguem a um resultado mais otimista, as teorias devessem servir aos terapeutas e não o contrário, para que estes pudessem trabalhar com elas e, às vezes até, apesar delas. Tal possibilidade, que acontece independente da linha teórica, funda-se em uma posição de certa rebeldia do terapeuta quanto a seus pressupostos teóricos (Roustang, 2001), permitindo-lhe criar um contexto em que a qualificação dos pacientes seja mais legítima (Gonzalez Rey, 1997) e a mudança, um projeto palpável (Erickson \& Rossi, 1980). Em outras palavras, o terapeuta assume marginalmente sua condição de sujeito, mas o problema é que o faz na maioria das vezes no silêncio de seu consultório. As condições epistemológicas para isso ainda estão por nascer. Porém, esses desafios devem ser aceitos para que tanto terapeuta como paciente não recebam mais a condenação de Sísifo.

\section{Capital e realidade: o problema do consumo}

A dimensão regulatória da psicologia clínica também está ligada com a relação que se estabeleceu nas sociedades ocidentais entre o conhecimento confiável da ciência e a produção de riquezas (Lyotard, 1979). O espantoso poder de transformação da natureza conseguido pela ciência trouxe um impacto considerável nas sociedades industriais nascentes, sobretudo por sua capacidade de produção em massa com ritmo, precisão e velocidades jamais atingidos. O conhecimento transformou-se, assim, em sinônimo de poder e domínio, o que se estabeleceu até mesmo em termos das relações entre países, tendo se tornado possíveis diferentes formas de colonização (Demo, 2000). Mais conhecimento gerado, mais riquezas produzidas para financiá-lo e assim sucessivamente. Como a psicologia, particularmente a clínica, nem sempre participou de modo direto dessa produção, a ela coube uma missão importante desde o início: a de promover explicações confiáveis sobre os indivíduos, sobretudo àqueles que não se adequassem às fieiras da produção (Foucault, 1972).

Contudo, trazendo-se a questão para um foco microssocial, pode-se notar também que a psicologia clínica manteve relações bastante interessantes com outros aspectos das sociedades de consumo, nas quais o acesso ao capi$\operatorname{tal}^{7}$ tornou-se uma referência de considerável importância. Tratou-se de uma espécie de identificador social, ligado aos projetos e trajetórias sociais, como também à regulação das relações entre os indivíduos (Gaulejac, 1987), sendo que a quantidade de capital transformou-se em um ponto de referência para a divisão de classes e para que os indivíduos de uma classe soubessem como se dirigir aos de sua mesma classe ou às classes de outras pessoas. As relações cotidia- nas mais diversas, como as de trabalho, de vizinhança, de matrimônio e família, tornaram-se, assim, profundamente permeadas por esse processo, a ponto de desenvolverem códigos e critérios muito específicos sobre o que caberia e competiria a cada um em uma dada situação.

Uma das primeiras conseqüências nesse sentido para a psicologia clínica foi a atribuição do termo cliente para os indivíduos que buscassem seus serviços. Sob o discurso de promover uma posição mais humana e ativa para os mesmos, em contraposição ao termo paciente por demais ligada à submissão institucional, muitas escolas acabaram por mostrar, sem o perceberem, que as práticas clínicas em geral estavam intensamente comprometidas com um grave problema de acesso ${ }^{8}$ (Gonzalez Rey, 1997; Neubern, 2003). O capital seria a condição para o ingresso nessa proposta pretensamente emancipatória, o que permitiria um trabalho calcado em maior liberdade e livre de empecilhos institucionais por vezes constrangedores e até desrespeitosos. Não é sem razões que esse tipo de proposta terapêutica remonta, desde Freud, a uma relação estreita com as classes detentoras de poder e capital (Castilho, 2002). Assim, somando-se ao problema da legitimidade já destacado, a ausência do capital criava uma distância considerável entre os indivíduos e as propostas terapêuticas que implicava, desde a falta de compreensão de cenários individuais e sociais (Gergen \& Kaye, 1998), até a impossibilidade de acesso a serviços de terapia. Essa é provavelmente uma das razões pelas quais a psicologia clínica ainda encontra grandes dificuldades para dialogar com as classes desfavorecidas, apesar dos inúmeros esforços nesse sentido (Sawaia, 1999; Sluzki, 1997).

O problema do consumo, no entanto, estaria também ligado de forma sutil a um outro processo simbólico em que as teorias parecem adquirir a condição de produto a ser consumido (Morin, 1990; Neubern, 2001). É muito provável que tenham vindo para ocupar um considerável vazio social, um vácuo deixado para que a palavra confiável da ciência se instalasse e oferecesse sentido sobre as razões e funcionamentos dos pensamentos e comportamentos das pessoas. Este talvez tenha sido um dos principais motivos para sua implantação e conquista dos setores sociais, o que abrangeu muitas práticas clínicas além da psicoterapia, como o psicodiagnóstico e, em termos extremos, boa parte das propostas de auto-ajuda (Demo, 2001), concretizadas em termos de workshops, cursos e livros. Contudo, mesmo sem recorrer à polêmica da autoajuda, pode-se considerar que as teorias em psicologia clínica passaram a oferecer explicações plausíveis sobre os indivíduos, o que permitiu um interessante processo de regulação entre elas, pois, sob o timbre da autoridade científica, tornou-se possível a identificação e a conseqüente antecipação quanto às características do interlocutor que mais demandassem explicações ou chamassem a atenção. É interessante notar como os rótulos parecem acompanhar os movimentos da moda e da mídia, como no caso das crianças hiperativas, os adolescentes que delinqüem para chamar a atenção, a síndrome do pânico, dentre outros.

A presente análise poderia ser bastante parcial caso se concentrasse apenas nos aspectos até aqui levantados, pois 
a psicologia clínica, estando imersa em uma sociedade de consumo, efetivamente deve expressar seu parecer sobre as questões vividas no cotidiano da mesma. Entretanto, o problema do consumo entra aqui como ponto decisivo, pois ele permite que as teorias possam ser consumidas, por vezes de forma irresponsável, sem que sejam criticadas, ou melhor, pensadas. As idéias são consumidas de uma forma muito semelhante aos psicotrópicos, como uma solução fácil para as angústias nascidas nas vicissitudes sociais, uma solução que afasta ou reifica o trabalho pessoal, as contradições relacionais e a própria condição de sujeito (Ehrenberg, 1998). Se fundamentadas sobre a solução simples ou o pessimismo exagerado, as teorias induzem os indivíduos à conformação e as instituições que as vendem nem sempre estão preocupadas em problematizá-las nos contextos específicos das vidas dos pacientes. Ou melhor, de seus “clientes”, no sentido mais legítimo do termo. Muitas vezes é como se o pagamento implicasse na abstenção da responsabilidade, da implicação pessoal e, sobretudo, da possibilidade de reflexão, de maneira que os pacotes assim comprados não pudessem ser transformados em termos críticos, pois estariam concebidos enquanto entidades transcendentes e acabadas que, além de tudo, receberiam o poderoso aval do mercado. O capital acaba contribuindo para a dimensão regulatória da psicologia clínica, apesar das contradições em que pode se implicar na sua relação com a subjetividade. É certo que ele também é subjetivado e seu simbolismo deve mesmo ser colocado em pauta para que o processo terapêutico caminhe favoravelmente (Madanes, 1997). Suas implicações na vida do sujeito são bastante intensas, principalmente considerando as dinâmicas das sociedades atuais em que possui um valor fundamental. Assim, é pertinente a consideração de que a terapia e os serviços clínicos sejam pagos, e que o dinheiro destinado a isso seja um indicador importante da dedicação do indivíduo.

Mas isso só até certo ponto. Porque na medida em que tal afirmação toma forma de uma regra reificada e em sintonia com as noções universalistas, perde-se boa parte da possibilidade de problematizar os vários sentidos presentes e subjetivados quanto ao capital. Mais que isso, pode-se nutrir a perspectiva de que a terapia dependa de questões que são externas ao sujeito e que o fato de pagar pelo serviço o exima de outras responsabilidades e implicações ${ }^{9}$. É como se a relação comercial implicasse que alguém especializado (o clínico), servindo-se de um conhecimento confiável (as teorias) devesse se ocupar das questões do cliente, sem que este, o maior interessado, necessariamente entrasse e problematizasse suas demandas, refletisse abertamente o trabalho terapêutico em seus cenários cotidianos e buscasse, enfim, a autonomia para gerir e construir seu próprio destino. Nesse sentido, pode ser destacada a criação de uma verdadeira cultura de consumo terapêutico, em que a terapia existe como um produto em si a ser consumido por um público que a demanda, mas sem que necessariamente isto se reverta em processos de mudança mais efetivos. Essas pautas interativas levam à criação de narrativas muito específicas que nem sempre são legítimas para os indivíduos (Gergen \& Kaye, 1998), mas que os ajudam a se endereçarem uns aos outros e a participar desse universo que compreende as relações entre terapeutas, clientes e instituições. Não é sem motivos que no cotidiano da clínica surgem, com freqüência, indivíduos (entre terapeutas e clientes) para quem o tempo de terapia é uma credencial importante, o que nem sempre é acompanhado por uma qualidade significativa.

Há, portanto, em muitos casos clínicos, grandes possibilidades de que a capacidade de criação, de descoberta, de utilização de recursos e mobilização emocional fiquem de fora ou sejam simplesmente banalizadas. O capital não é em si um problema, como a terapia não é em si um produto: ambos estão inseridos numa rede de significações, sentidos e cenários sociais e é nessa mesma rede que devem ser pensados conscientemente seus respectivos usos. Se é certo que a sociedade se complexifica e exige cada vez mais respostas dos especialistas (Ehrenberg, 1998), não é menos correto que tais demandas sejam acompanhadas e desenvolvidas por uma reflexão ética e responsável. Afinal, sendo a psicologia clínica também uma construção da sociedade, ela não pode eximir-se da responsabilidade de se refletir, sobretudo, no que diz respeito a seus impactos nessa sociedade.

\section{Conclusão: por uma ética interna}

As considerações desenvolvidas até aqui remetem a problemas éticos variados, mas, sobretudo em termos do que a reflexão epistemológica desenvolve. Não se deve considerar que a dimensão regulatória da psicologia clínica tenha contribuído para que tal ciência se transformasse em uma ciência antiética ou manipuladora e sem escrúpulos. Mas deve-se conceber que a psicologia clínica é fruto das sociedades ocidentais, onde a regulação se impôs sobre a emancipação (Santos, 1989; 2000). Assim sendo, não cabe aqui restringir a discussão à condição ética dos psicólogos como se fosse o único e exclusivo foco de produção de conhecimento. Compõem, em sua maioria, gerações de pensadores e profissionais que se imbuíram e acreditaram nos ideais científicos, na perspectiva de oferecer à sociedade serviços e reflexões baseados num conhecimento confiável sobre a psique humana. A discussão ética deve abranger, porém, as variadas implicações de um conhecimento disjuntivo, que na maior parte de seus momentos, contribuíram para a dimensão regulatória, para uma psicologia mais preocupada em explicar e compreender do que oferecer opções de criação e reconhecimento do sujeito.

É provável que o grande problema nesse sentido tenha sido a compreensão da ética como algo externo ao conhecimento, que contempla e julga uma realidade que já está dada e simplesmente se impõe. Trata-se da concepção já denunciada por certos autores (Gergen, 1996; Neubern, 2001) do discurso comprometedor de que a ciência simplesmente deveria revelar como as coisas são para que depois se discutisse como deveriam ser. Remonta à idéia de que o homem só seria capaz de revelar a natureza sem muitas opções no que se refere à forma de compreendê-la, uma natureza à parte dele, de sua comunidade científica e da própria sociedade em que 
vive. O grande problema ético nesse sentido foi a falta de opções que subjugou os indivíduos ao conhecimento de tal modo que o sujeito passou a ser proibido. Para os pacientes não houve muitas alternativas de compreensão e desenvolvimento de seus próprios sentidos e significados, enquanto que para os terapeutas a reflexão epistemológica, quando não ocupou um lugar conciliatório e conformista, foi considerada como algo subversivo e herético ${ }^{10}$ (Gonzalez Rey, 1997; Koch, 1981). Embora os clínicos tenham participado da construção e manutenção de teorias e instituições, acabaram por se tornar vítimas de tais conhecimentos que colonizaram seus próprios pensamentos e potencial criativo.

Assim sendo, uma vez que tal problema é posto, considera-se que uma ética interna remete aos questionamentos sobre as conseqüências e implicações das propostas epistemológicas do conhecimento em suas relações com a sociedade. Esse tipo de questionamento pode levar a reformulações profundas que não apenas remetem a transgressões de paradigma, mas principalmente tocam numa relação distinta entre os homens e o conhecimento que produzem. Para isso é preciso uma nova forma de construção do conhecimento em que as dicotomias sejam superadas e as barreiras dissolvidas de maneira que seja possível ao homem se enxergar naquilo que produz para que possa assumir com mais consciência as conseqüências de suas próprias construções. Em outras palavras, é preciso que o sujeito possa se enxergar no objeto que estuda para que, ao invés de simplesmente buscar dominá-lo, seja possível dialogar com ele sem destruí-lo, pois, nessas circunstâncias, qualquer tentativa de imposição ou domínio sobre a natureza traria à tona as conseqüentes retaliações e problemas na sociedade. Isto porque, nessa perspectiva, a natureza humana seria em si um processo social e subjetivo, de modo que seus diferentes objetos e sistemas trariam de modo mais explícito as relações com a própria sociedade que os gerou. A citação a seguir pode sintetizar de forma conclusiva essa idéia.

Hoje não se trata tanto de sobreviver como de saber viver. Para isso é necessária uma outra forma de conhecimento, um conhecimento compreensivo e íntimo que não nos separe e antes nos una pessoalmente ao que estudamos. A incerteza do conhecimento, que a ciência moderna viu como limitação técnica destinada a sucessivas superações, transforma-se na chave do entendimento de um mundo que mais do que controlado tem de ser contemplado. Não se trata mais do espanto medieval perante uma realidade hostil possuída do sopro da divindade, mas antes da prudência perante um mundo que, apesar de domesticado, nos mostra a cada dia a precariedade do sentido da nossa vida por mais segura que esteja ao nível da sobrevivência. (Santos, 1987, pp. 53-54)

\section{Agradecimentos}

O autor agradece à Capes, pelo financiamento do projeto, e à Profa. Dra. Albertina Mitjans Martinez, pela sugestão desse artigo.

\section{Referências}

Anderson, H. (1997). Conversation, language and possibilities. Nova York: Basic Books.

Anderson, H., \& Goolishian, H. (1988). Human systems as a linguistic systems: preliminary and evolving ideas about the implications for clinical theory. Family Process, 27, 371-393.

Ausloos, G. (1995). La compétence des familles. Paris: Érès.

Bachelard, G. (1996). A formação do espírito científico. Rio de Janeiro: Contraponto (trabalho original publicado em 1938)

Barus-Michel, J., \& Giust-Desprairies, F. (2000). Pour une épistémologie de la psychologie sociale clinique. Bulletin de Psychologie, 53(3), 317-323.

Bergeret, J. (1974). La personnalité normale et pathologique. Paris: Bordas.

Castilho, J. (2002). A vida e a técnica de Sigmund Freud. As bases para a psicanálise infantil. Dissertação de Mestrado não-publicada, Universidade de Brasília, Brasília, DF.

Castoriadis, C. (1975). L'institution imaginaire de la société. Paris: Seuil.

Chertok, L., \& Stengers, I. (1989). Le coeur et la raison: l'hypnose en question, de Lavoisier à Lacan. Paris: Payot.

Demo, P. (2000). Metodologia do conhecimento científico. São Paulo: Atlas.

Demo, P. (2001). A dialética da felicidade. Petrópolis: Vozes.

Durkheim, E. (1995). Le suicide. Paris: Presses Universitaries de France. (trabalho original publicado em 1897)

Ehrenberg, A. (1998). La fatigue d'être soi: dépression et societé. Paris: Odile Jacob.

Erickson, M., \& Rossi, E. L. (1980). The collected papers of Milton H. Erickson. Nova York: Irvington.

Foucault, M. (1972). Histoire de la folie à l'âge classique. Paris: Gallimard.

Freud, S. (1996). A interpretação dos sonhos. In Edição standard brasileira das obras completas de Sigmund Freud (vol. IV-V, pp. 1-752). Rio de Janeiro: Imago. (trabalho original publicado em 1900)

Gaulejac, V. (1987). La névrose de classe. Paris: Hommes et Groupes.

Gergen, K. (1996). Realidades y relaciones. Barcelona: Paidós.

Gergen, K., \& Kaye, J. (1998). Além da narrativa na negociação do sentido terapêutico. In S. Mc Namme e K. Gergen (Orgs.), A terapia como construção social (pp. 201-222). Porto Alegre: Artes Médicas.

Gonzalez Rey, F. (1997). Epistemología cualitativa y subjetividad. Havana: Pueblo y Educación.

Graves, R. (1967). Les mythes grecs. Paris: Fayard.

Guattari, F. (1979). L'inconscient machinique. Essais de schizo-analyse. Fontenaysous-Bois: Recherches.

Koch, S. (1981). The nature and limits of psychological knowledge. American Psychologist, 36(3), 257-269.

Lyotard, J. (1979). La condition postmoderne. Paris: Minuit.

Madanes, C. (1997). O significado secreto do dinheiro. Campinas: PsyII.

Mahoney, M. (1991). Human change process. Nova York: Basic Books.

May, R., Angel, E., \& Ellenberger, H. (1967). Existencia: nueva dimensión en psiquiatría y psicología. Madri: Gredos.

Melchior, T. (1998). Créer le réel. Hypnose et thérapie. Paris: Seuil.

Morin, E. (1990). Science avec conscience. Paris: Seuil.

Morin, E. (1991). La Méthode 4. Les idées. Paris: Seuil.

Natan, T. (1999). Manifeste pour une psychopathologie scientifique. In T. Natan \& I. Stengers (Orgs.), Médecins et sorciers (pp. 9-113). Paris: Synthelabo.

Neubern, M. (2001). Três obstáculos epistemológicos para o reconhecimento da subjetividade na psicologia clínica. Psicologia Reflexão \& Crítica, 14(1), 242-252.

Neubern, M. (2003). Passos para uma epistemologia complexa da psicologia clínica. Tese de doutorado não-publicada, Universidade de Brasília, Brasília, DF.

O’Hanlon, W., \& Wilk, J. (1987). Shifting contexts. Nova York: Guilford.

Pagès, M. (1993). Psychothérapie et complexité. Paris: Hommes et Perspectives.

Perls, F. (1973). The gestalt approach and eye witness to therapy. Palo Alto: Science and Behavior Books.

Prigogine, I., \& Stengers, I. (1979). La nouvelle alliance. Paris: Gallimard. Rogers, C. (1961). On becoming a person. Boston: Houghton-Mifflin. 
Roustang, F. (2001). Tout fait ventre. In A. Delourne (Org.), Pour une psychothérapie plurielle (pp. 94-110). Paris: Retz.

Santos, B. S. (1987). Um discurso sobre as ciências. Porto: Afrontamento.

Santos, B. S. (1989). Introdução a uma ciência pós-moderna. São Paulo: Graal.

Santos, B. S. (2000). A crítica da razão indolente. São Paulo: Cortez.

Sawaia, B. (1999). As artimanhas da exclusão. Petrópolis: Vozes.

Silva, B. (Org.). (1986). Dicionário de ciências sociais. Rio de Janeiro: Fundação Getúlio Vargas.
Skinner, B. F. (1993). Ciência e comportamento humano. São Paulo: Martins Fontes. (trabalho original publicado em 1953)

Sluzki, C. (1997). A rede social na prática sistêmica. São Paulo: Casa do Psicólogo.

Stengers, I. (1995). L'invention des sciences modernes. Paris: Flammarion.

Van den Berg, J. (1999). O paciente psiquiátrico. Campinas: Psy II. (original publicado em 1955)

Weber, M. (1951). Essais sur la théorie de la science. Paris: Plon.

1 O presente artigo deriva da tese de doutorado do autor Passos para uma epistemologia complexa da psicologia clínica, defendida no Instituto de Psicologia da Universidade de Brasília.

${ }^{2} \mathrm{O}$ termo modernidade aqui adotado provém da pretensão científica de um acesso privilegiado e isomórfico do real, o que está presente nas escolas de inspirações behavioristas, psicanalistas, fenomenológicas e humanistas (Gergen \& Kaye, 1998), apesar de suas críticas ao projeto de ciência. A idéia de pós-modernidade neste trabalho refere-se a um conjunto de movimentos que, apesar de distintos, preconizam a crítica ao isomorfismo e acentuam a natureza construída da realidade por meio de processos intersubjetivos (Gergen \& Kaye, 1998; Lyotard, 1979; Santos, 1989).

${ }^{3}$ É curioso notar que boa parte das escolas de psicologia clínica surgiu a partir da divergência quanto a um mestre fundador (Neubern, 2003). Os integrantes excluídos fundaram novos grupos em nome de outro mestre e retomaram o processo de institucionalização. Vários discípulos de Freud, como Jung, Adler, Reich e Perls seguiram esse caminho.

${ }^{4}$ A terapia pessoal pode possuir um discurso coerente e uma utilidade bastante prática no sentido de preparar o clínico para a atividade profissional. Entretanto, ela possui também uma dimensão regulatória na medida em que afasta os críticos competentes e a possibilidade de reflexão aberta (Chertok \& Stengers, 1989). Com efeito, os clínicos também são submetidos a terapias de teor univeralista que deixam margem a inúmeros questionamentos. Se a terapia é uma questão de momento, porque numerosos cursos de formação determinam um período e uma carga horária para que as mesmas ocorram? Porque muitas vezes a diferença entre terapias didáticas e não-didáticas parece ser diluída e esquecida? A terapia obrigatória não seria uma contradição?

${ }^{5}$ Deve-se considerar que as influências humanistas, embora influenciadas pela idéia de natureza humana, fizeram forte oposição à noção patológica. Esta crítica é, portanto, mais voltada para as inspirações psicanalíticas. Mesmo assim, uma crítica pós-moderna também poderia destacar aspectos incapacitantes presentes nas propostas humanistas, principalmente devido ao problema da legitimidade (Gergen, 1996).

${ }^{6}$ Trata-se de um deus da mitologia grega que, por resolver vários problemas enganando outros deuses, foi condenado a empurrar uma pedra eternamente montanha acima, sem jamais atingir o cume. Toda vez que atingisse certo ponto, desceria rolando com a pedra e seria obrigado a retomar a tarefa (Graves, 1967).

${ }^{7}$ Embora o termo capital possua muitas definições, aqui ele será tomado como um conceito ligado à produção e circulação de riquezas (Silva, 1986), o que acaba sendo um dos definidores das diferenças de classe e perspectiva sociais (Gaulejac, 1987).

${ }^{8} \mathrm{O}$ problema do acesso não seria apenas para os indivíduos que necessitassem de auxílio, mas também na formação dos psicólogos, o que coloca numerosas questões. Quem seriam os psicólogos que podem ter acesso a uma boa faculdade ou curso de formação? A massificação do ensino superior que tem ocorrido no país resolveria o problema? Que pessoas poderiam pagar os cursos das instituições privadas? Seriam eles de qualidade?

${ }^{9}$ A experiência de serviços gratuitos, ou pagos conforme a renda, que são oferecidos à comunidade, pode demonstrar que qualquer afirmação geral desenvolvida nesse sentido corre o risco de tornar-se duvidosa.

${ }^{10}$ Daí o seu considerável atraso na psicologia, mesmo com relação às demais ciências sociais e humanas (Gonzalez Rey, 1997).

Maurício da Silva Neubern, doutor em Psicologia pela Universidade de Brasília, é professor no Centro Universitário de Brasília. Endereço para correspondência: SQS 408, Bloco T, apto. 206; Brasília, DF; CEP 70257-200. Tel: (61) 3244-3069. E-mail: mneubern@hotmail.com 